\title{
Review of Driver Seat Suspension using MR Fluid Damper
}

\author{
Swapnil Hatwalane*,B. S. Kothavale, Akshay Ohol and Girish Palve \\ Mechanical Engineering Department, MITCOE, SPPU, Pune, India \\ Accepted 02 March 2016, Available online 15 March 2016, Special Issue-4 (March 2016)
}

\begin{abstract}
The automobile market become competitive based on the dynamic comfort of a seat. It is through the seat that vibrations enter the body of the driver in large proportion. In long distance driving, the driver feels headache and body pain due to the vibration of the seat. Today in the world of competition every automobile industry wants to give some more features in their design to get attraction of the customers and the comfort is very important feature to get attraction of the buyers. Also the buyers are also aware of comfort of vehicles. Till recently, a lot of focus has been on a static comfort of seats, while limited attention has been paid on dynamic comfort. Semi active control system are reliable and versatile as also they consume less power, hence they are becoming popular. In a particular Magnetorheological (MR) fluids have been found to be effective for use in vibration control actuators. The paper gives a glimpse of design of driver seat suspension system model with MR Fluid damper under harmonic excitation with finite element. We have studied the response of MR damper to vibration, which plays an important role in defining the dynamic comfort.
\end{abstract}

Keywords: MR fluid Damper, Car Driver seat, Driver seat suspension system

\section{Introduction}

Comfort of the driver plays a vital role in the passenger safety, fatigue during long drive, and drivability in heavy traffic. Comfort is nothing but absence of any discomfort. Not only pollution and performance, economy but also safety and comfort are major factors to consider. Seat must avoid the vibration transmitted from the road surfaces and power train, in order to avoid back disorder, hand eye coordination, vision impairment etc. and also the long time exposure to vibration causes fatigue to the passenger and hence to avoid this vibration we require a vibration isolator i.e. seat suspension system. With this we are heading towards the study of driver seat suspension necessity, with the help of MR fluid damper to evaluate our objective.

The comfort level and ride stability of any vehicle are two most significant factors in evaluation of vehicle. In particular, it has been also seen that magneto rheological (MR) fluids damperis good for vibration reduction applications. MR fluids are magnetic analogs of electro rheological (ER) fluids and typically consist of micrometer-sized, magnetically polarizable particles dispersed in a carrier medium such as mineral or silicone oil. When a magnetic field is

*Corresponding author: Swapnil Hatwalane passed to the fluid, particle get in the forms chain and the fluid shows properties similar to that of ER fluid and become semisolid.

This governable change of state with some achievable characteristics such as high strength, good stability, wide operational temperature range and quick response time gives rise to isolation and suspension system applications. With the use of MR fluid damper and cast iron plates, suspension assembly for driver seat is going to develop and damping effect of damper towards seat vibrations will be describe.

\section{Literature review}

A MR fluid damper which is nothing but semi-active controlling devices that uses MR fluids to get required controllable damping forces. S Karajagikar, N R Rajhans, B B Ahuja, R G Rajhans in their experimentation for two different cars RMS acceleration range as per ISO comfort index is near to fairly uncomfortable 0.007 - 0.008 and hence we have conclude that suspension system is necessary for any vehicle driver seat. As per reference standard ISO2631-1[1997] ride comfort index is the qualitative measure of comfort, with the help of this, comparatively we can study seat suspension system with MR damper. 
Table 1 Ride comfort index

\begin{tabular}{|c|c|}
\hline RMS Acceleration $\mathbf{( k m} / \mathbf{s}^{\mathbf{}}$ ) & Comfort Index \\
\hline Less than 0.000315 & Not Uncomfortable \\
\hline 0.000315 to 0.00063 & A little Uncomfortable \\
\hline 0.0005 to 0.001 & Fairly Uncomfortable \\
\hline 0.0008 to 0.0016 & Uncomfortable \\
\hline 0.00125 to 0.0025 & Very Uncomfortable \\
\hline Greater than 0.002 & $\begin{array}{c}\text { Extremely } \\
\text { Uncomfortable }\end{array}$ \\
\hline
\end{tabular}

Martin Orecny, Stefan Segla, Robert Hunady, Zelmira Ferkova. In their experimentation they used two models

One with dynamic absorber and other without dynamic absorber.They calculated stiffness, displacement, damping coefficient numerically and hence they concluded that effect of dynamic absorber is negligible because the Magnetorheological fluid damper [3] reduced the maximum amplitude to values that are almost unnoticeable for the driver situated on the seat so by using MR fluid damper alone vibrations can be reduce.

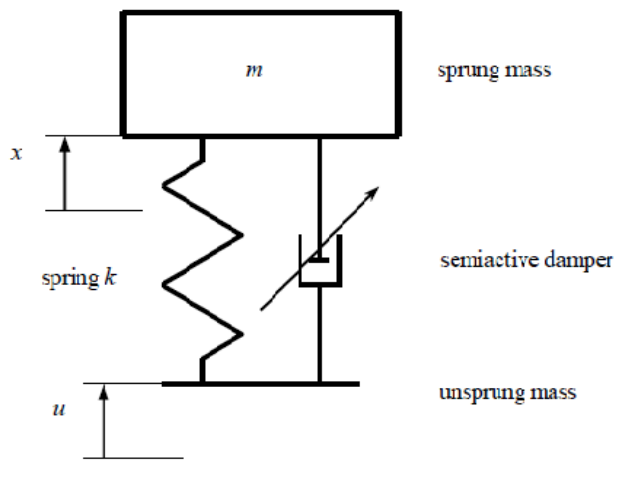

Fig. 1Seat Suspension

Mahmoud El-Kafafy, Samir M. El-Demerdash, Al-Adl Mahamed Rabeih analyzes 3 types of damper namely Active type, Passive type and Semi-Active type i.e MR damper to get best ride comfort through suspension system in any vehicle for passengers and driver. In this the results are plotted in the form of graphs by experimentation and also in MATLAB software. There are 3 types of mechanical models in which fuzzy models and neural network are not used because with its non linearity, ramification and can not be able to get desired damping force in an open control system.So they used Bouc-Wen which is described by Spencer et al, used commonly to elaborate the MR damper hysteretic characteristics.In this by experimentation the controlled MR damper has high vibration restitution in comparing with the passive MR damper also controllable MR damper has better that is $24 \%$ of vehicles road holding when compared with fully active and $22 \%$ on ideal semiactive suspension system.

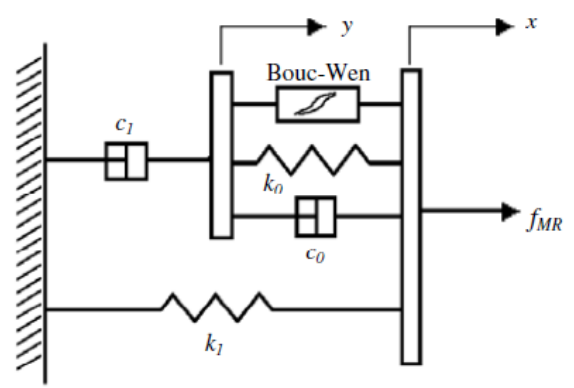

Fig. 2 Mechanical model of MR damper

The hysteretic behavior in the MR damper was depicted with the help of Bouc-Wen model. The mechanical actualizationschematic diagram of the MR damper is shown in figure 2. The phenomenologically mechanical model is governed by the following equations.

$\dot{y}=\frac{1}{c 0+c 1}[\alpha z+k 0(x-y)+c 0 \dot{x}]$

$\dot{z}=-\gamma|\dot{x}-\dot{y} \| z|^{n-1} z-\mu(\dot{x}-\dot{y})|z|^{n}+A(\dot{x}-\dot{y})$

$f M R=c 1 \dot{y}+k 1(x-x 0)(3)$

W H Liao1 and C Y Lai in their paper did harmonic analysis of MR damper to investigate characteristics of single degree of freedom system with MR fluid damper through experimental studies. Spencer et al uses the mathematical model of MR damper. Bouc-Wen model used for determine hysteretic behavior in the damper. To optimize different parameters Least square optimization method is used. In experimental setup dynamic response of damper can measure for prescribed wave forms and frequencies. Vibration system (labworks Inc. LW-127-500) is used to produce excitation for damper. Laser vibrometer is used for measuring velocity and displacement.

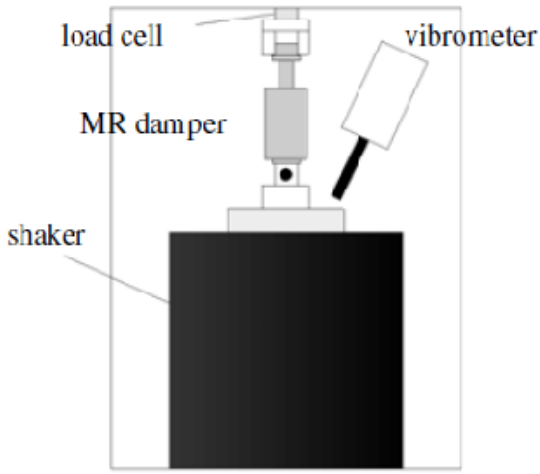

Fig. 3 Schematic test setup for the MR damper

From this experimentation author developed forcedisplacement, force-velocity loop. In this paper author compared effect of simple viscous damper, MR damper and Semi-active MR damper and concluded that Semiactive MR damper is more effective for vibration control. 
Also, Attia E. M., Ayman .F.Z, El Gamal H.A, El Souhily B.M in their experimentation, by using Spencer's MR damper model suspension using MR damper and conventional damper the frequency and amplitude of vibration is determined. The results are plotted at constant speed, voltage and height of hump with considering different types of road. They concluded that MR damper is more efficient to reduce vibration as compare with classical type of damper also the effect of road irregularities on driver can be reduced and also the use of MR dampers improves the function of vehicle suspension.

With reference of papers, The MR damper used in this study is RD-1005-1, manufactured by Lord Corporation. The length of the damper is $20.83 \mathrm{~cm}$ in its extended position. It has a $5 \mathrm{~cm}$ stroke. The maximum current to the electromagnet in the magnetic choke is $2 \mathrm{~A}$ and the coil resistance is $5 \mathrm{ohm}$. To evaluate the performance of MR dampers in vibration control applications and to take full advantage of the unique features of these devices, a model is needed to accurately describe the action of the MR damper.
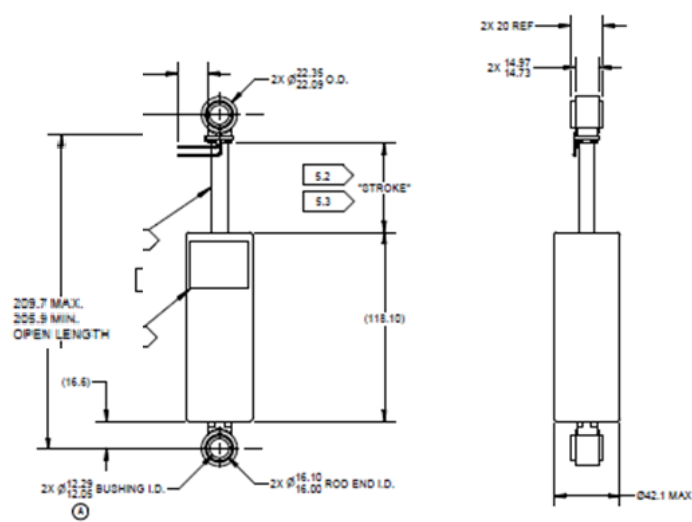

Fig. 4MR damper assembly short stroke

Francis Joseph, Dr. Jason Isaac, T J Paulson concluded that according to different road conditions dynamic comfort of seat, Ride Comfort Index and Transmissibility of car seats, The work "Low Frequency Vibration Analysis on Passenger Car Seat" [7] was done successfully to find the dynamic comfort of the passenger car seat under varying road terrains. A test setup for measuring the vibration transmissibility of the passenger car seat in real time condition has been developed. Using the test methodology, transmissibility of the seat under specified test conditions were identified and the relation of transmissibility with road terrain is found. From the experiment conducted under rough and smooth road terrain, it is found that the transmissibility will vary with respect to terrain. ISO 2631 effectively characterizes the different vehicles for their ride comfort. Ride comfort index calculated from the acceleration value has identified the comfort of each car in the rough and smooth terrain.

Hence with the above mentioned literature survey, we studied how MR damper is providing sufficient damping for driver seat vibrations.

\section{Discussion}

After studying the different research papers of MR damper and automotive ride comfort control system, with different approaches, methodologies and experimentations the suspension system will overcome the problem that occurs in the car or automobile related to the driver discomfort.

\section{Methodology}

Suspension system uses MR fluid damper as it is semi active control and MR damper filled with magneto rheological fluid which provides sufficient damping with changes in its viscosity. With the same principle, we are developing suspension system to absorb driver seat vibrations coming from foundation. We use cast iron plates to support MR damper assembly and for better response we use 2 dampers in parallel configuration.

\section{Scope}

Driver seat is important aspect while defining comfort of driver in a moving vehicle. Comfort of the driver plays a vital role in the passenger safety, fatigue during long drive, and drivability in heavy traffic. Comfort means absence of any discomfort, so designing driver seat suspension system with MR fluid damper to improve the human comfort is a necessity and much research are going with the same objective In future every vehicle will have good comfort and safety in every perspective. So this project will serve as one of the advanced technology in future and will be installed in every vehicle. Seeing towards our basic version, there are some ideas for the future development of driver seat suspension System.

1) Use one MR damper and use different springs for system arrangement for cost reduction.

2) With the considerations of bio mechanics parameter, suspension system may develop with respective sensors to increase sensitivity.

3) Develop a system consist of MR damper and Dynamic absorber which also consist of MR damper for good performance.

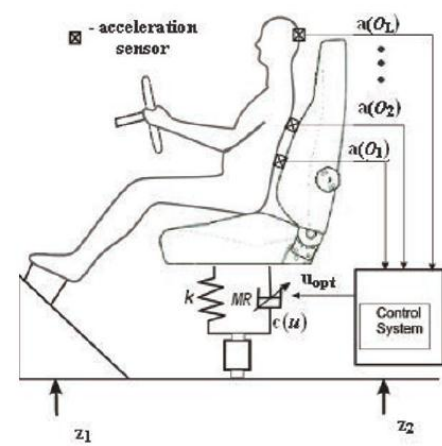

Fig. 5 MR damper suspension system for seat 


\section{Conclusions}

Almost within some year every automobile admirer wants car with advanced technology, comfort and safety. People want something new in their life. For seat vibration control, a model consisting with MR damper, Performances and characteristics of the seat suspension system with different literatures experimentation have been evaluated through. Based on results accomplished, the following conclusions have been drawn, development of system which gives better damping for seat vibrations. Also, as per driver seat position damper gives appropriate performance. So to reduce discomfort and instability the research and development of Design and vibration analysis of driver seat by using mr fluid damper system improves driver comfort and ride stability

\section{References}

J S Karajagikar, N R Rajhans, B B Ahuja, R G Rajhans. (201126-0119), Vibration analysis on driver seat for small cars

ISO 2631-1(1997):Mechanical Vibration and Shock evaluation of Human Exposure to Whole Body Vibration Part 1
Martin Orecny, Stefan Segla, Robert Hunady, Zelmira Ferkova.. (2014-338-344) Application of a Magnetorheological fluid damper and a dynamic absorber for a suspension of seat

Mahmoud El-Kafafy, Samir M. El-Demerdash, Al-Adl Mohamed Rabeih.(2012.44024) Automotive Ride Comfort Control Using MR Fluid Damper. Eng.

W H Liao1 and C Y LaiS.11 (2002)Smart Harmonic analysis of a magnetorheological damper for vibration control. Mater. Struct. 11 (2002)288-296PII:S0964-1726(02)34308-

Lord Corporation Web Site, 2004. http//www.lord.com

Francis Joseph, Dr. Jason Issac, T J Paulson

Low frequency vibration analysis on passenger car seat.(ISSN 2229-5518)

Dyke S J, Spencer B F Jr, Sain M K and Carlson J D 1996

Modelling and control of magnetorheological dampers for seismic response reduction Smart Mater. Struct. 5565-75

Andrzej Gagorowski. Controlling the magnetorheological suspension of a vehicle seat including the biomechanics of the driver.

Spencer B F Jr, Dyke S J, Sain M K and Carlson J D 1997 Phenomenological model of magnetorheological damper J.Eng.Mech 123230-8 